\title{
Gesture technique analysis of the craniocervical mandibular complex in string and wind instrumentalists
}

\author{
Miguel Pais Clemente ${ }^{1 *}$, Joaquim Mendes ${ }^{2}$, André Moreira ${ }^{3}$, Catarina Aguiar Branco ${ }^{4}$, Afonso Pinhão Ferreira ${ }^{5}$ and José Manuel Amarante $^{6}$ \\ ${ }^{1} \mathrm{PhD}$ Student, MD, Faculty of Dental Medicine Porto, Portugal \\ ${ }^{2}$ Assistant Professor, INEGI, Labiomep, Faculty of Engineering, University of Porto, Portugal \\ ${ }^{3}$ Post-graduation student, Faculty of Dental Medicine Porto, Portugal \\ ${ }^{4}$ Assistant Professor, Department of Temporomandibular Disorders, Faculty of Dental Medicine, University of Porto, Portugal \\ ${ }^{5}$ Full Professor, Department of Orthodontics, Faculty of Dental Medicine, University of Porto, Portugal \\ ${ }^{6}$ Full Professor, Department of Surgery, Faculty of Medicine, University of Porto, Portugal
}

\begin{abstract}
Introduction: Nowadays a professional career may reflect the way of living. Musicians are a group of people where musculoskeletal complaints are common. The musical gesture of an instrument is not always symmetrical. Moreover, for a professional musician, a musculoskeletal disorder may be related to multiple hours playing in a prolonged and incorrect posture. The main goal of this investigation was determining the head and neck posture during a musical performance in wind and string instrumentalists.
\end{abstract}

Methods: The musical gesture of 41 wind instrumentalists and 16 string instrumentalists was analysed using an accelerometer placed on the glasses. The signal was read by the program ZSTAR Graphical User Interface ${ }^{\circledR}$. For each participant it was recorded the degree of movement of the head and neck for posteriorly define a medium degree of inclination in an anterior-posterior axis and left-right axis.

Results: All the musicians present an anterior flexion of the head with more than $20^{\circ}$, compared to the upright position when looking straight forward. Transverse flautists, violinists, violoncello instrumentalists play with their heads tilted to the right because of the musical gesture. The bassoon player was the only instrument alist that presented a tendency of having a lateral flexion of the head to the left side.

Conclusions: The wireless 3D accelerometer is capable to track the orientation of the string and wind instrument craniocervical mandibular complex towards the gravity during music performance.

\section{Introduction}

String and wind instrumentalists are exposed to a highly demanding physical and cognitive activity. The complete understanding of the musical gesture of these individuals can be relevant from the clinical point of view, in order to fulfil a better comprehension of the adopted posture of these musicians during their performance. There are certain health care providers, among others, Physiatrists, Orthopaedics, Dentists and Plastic Surgeons, that can benefit from the application of biomedical devices to achieve a biomechanical characterization and quantification of certain anatomic sites and kinetic chains of our body.

In the dentistry particular scope, this can be relevant regarding the craniocervical mandibular complex (CCMC), where muscular hyperactivity (like in the masseter and anterior temporal muscles), a constant temporomandibular joint overloading, kinetic chains and movement dysfunctions involving the CCMC and the scapular joints, can develop temporomandibular disorders. On the other hand, the constant, compensatory, synergic or antagonist muscular contractions and the compensatory kinetic chains, like in the anterior and posterior cervical regions, can lead to postural and movement disorders.

An incorrect musical technical gesture may lead not only to a bad performance, but also predispose the musician for specific technopathies [1]. Among professional musicians it is common the occurrence of musculoskeletal complains resultant of their profession. Kok, et al. 2015 made a systematic review on this matter and conclude that for professional musicians the prevalence of musculoskeletal complaints range between 9 to $68 \%$, in one year the prevalence of a musculoskeletal disorder range between 41 and $93 \%$ and in a lifetime can achieve values going from 62 to $93 \%$ [2]. Furthermore, also Kok, et al. in 2013, reported that musicians have much more musculoskeletal complaints when comparing a non-musician population. The most common areas where this technopathies emerge are at the level of the neck and shoulders, which makes conceivable that musicians have more upper body-part complaints [3].

The development of a musculoskeletal disorder (MSD) in a musician is dependent of multiple factors, non-modifiable and modifiable. A musician has physical risk factors non-modifiable, such as the instrument played, gender, playing conditions, joint laxity and

${ }^{\star}$ Correspondence to: Miguel Pais Clemente, $\mathrm{PhD}$ Student, MD, Faculty of Dental Medicine Porto, Portugal, E-mail: miguelpaisclemente@hotmail.com

Key words: accelerometer, musculoskeletal disorders, musicians, posture

Received: December 03, 2018; Accepted: December 13, 2018; Published: December 17, 2018 
the repertoire. The minimally modifiable risk factors are the overload, posture, biomechanics, instrumental technique, physical condition and injury management. Moreover, psychosocial factors also have an important role to the development of MSDs, some of them are anxiety, depression, educational institution, social phobia and personality traits [4-8]. A particular MSD may affects the musician's health condition, but also his/her career. The pain prevalence is high among musicians affects the musical performance varying between (25.4 to 84.4\%) [9].

The present study pretends to look deeper in two of the risk factors mentioned above. The instrument that is being played and the gesture technique (posture) that the instrumentalist adopts while performing. The instrument size, anatomy, weight and asymmetry will invariably influence the gesture technique of a musician. Ramella, et al. 2014 reported that to play an asymmetric instrument may expose musicians to an increased risk of non-optimal postures and to a worsened postural disorder when present [10]. The correct posture of a musician while playing is a prophylactic measure to avoid spinal overload and the development of postural defects. This simple aspect may decrease the incidence of an MSD and is correlated with the degree of disability and pain intensity [11].

The study of body posture, the cervical movement and its kinematics is not recent and have been conducted in different medical areas and with different type of resources. For example, Amiri, et al. used a noninvasive electromagnetic device 3-Space Fastrak to track the cervical movement in three-dimensional axis [12]. Additionally, to study the normal kinematics of the upper cervical spine during the flexion and rotation, Takasaki, et al. conducted a research on 45 participants that went through a magnetic resonance imaging exam [13]. Furthermore Edmondston, et al. 2004 to study the cranio-cervical posture used a three-dimensional goniometer [14]. Also, the goniometer has been used to determine the range of motion in spasmodic torticollis by Salvia, et al. [15]. Later in 2010, Minami, et al. found that the triaxial piezoelectric accelerometer could serve as a diagnostic tool to evaluate the jaw movement in general dental practice [16].

Therefore, the main goal of the present study was to analyze and quantify the musical gesture technique of the CCMC, more specifically the degree of the head and neck flexion anterior-posteriorly and laterally in wind and string instrumentalists.

\section{Materials and Methods}

The sample of the present study was composed by 57 musicians, 41 were wind instrumentalists and 16 were string instrumentalists. All musicians declared to be healthy and were studying at the School of Music and Performing Arts of Porto (ESMAE).

Forthisresearcha3DMEMSaccelerometer(MicroElectroMechanical Systems) was used. The model used was Freescale MMA7455L $\pm 2 \mathrm{~g}$ which has the dimensions of $3 \times 5 \times 1 \mathrm{~mm}$. The device was connected to a small circuit board that allows to have a wireless communication with a computer using ZigBee $2.4 \mathrm{GHz}$ protocol. To read the signal from the accelerometer, the program ZSTAR Graphical User Interface was used. To a proper use regarding the musical performance of the participants, the accelerometer was adapted to a pair of glasses.

Before starting the measurements, the musician is asked to look straight forward for 5-10 seconds to get the reference position (Figure 1). After the calibration, the musician played for 20-30 seconds the play "Ode to Joy" by Beethoven, where it was possible to record the range of motion for both axis Before starting the measurements, the musician is asked to look straight forward during 5-10 seconds to get the reference position.

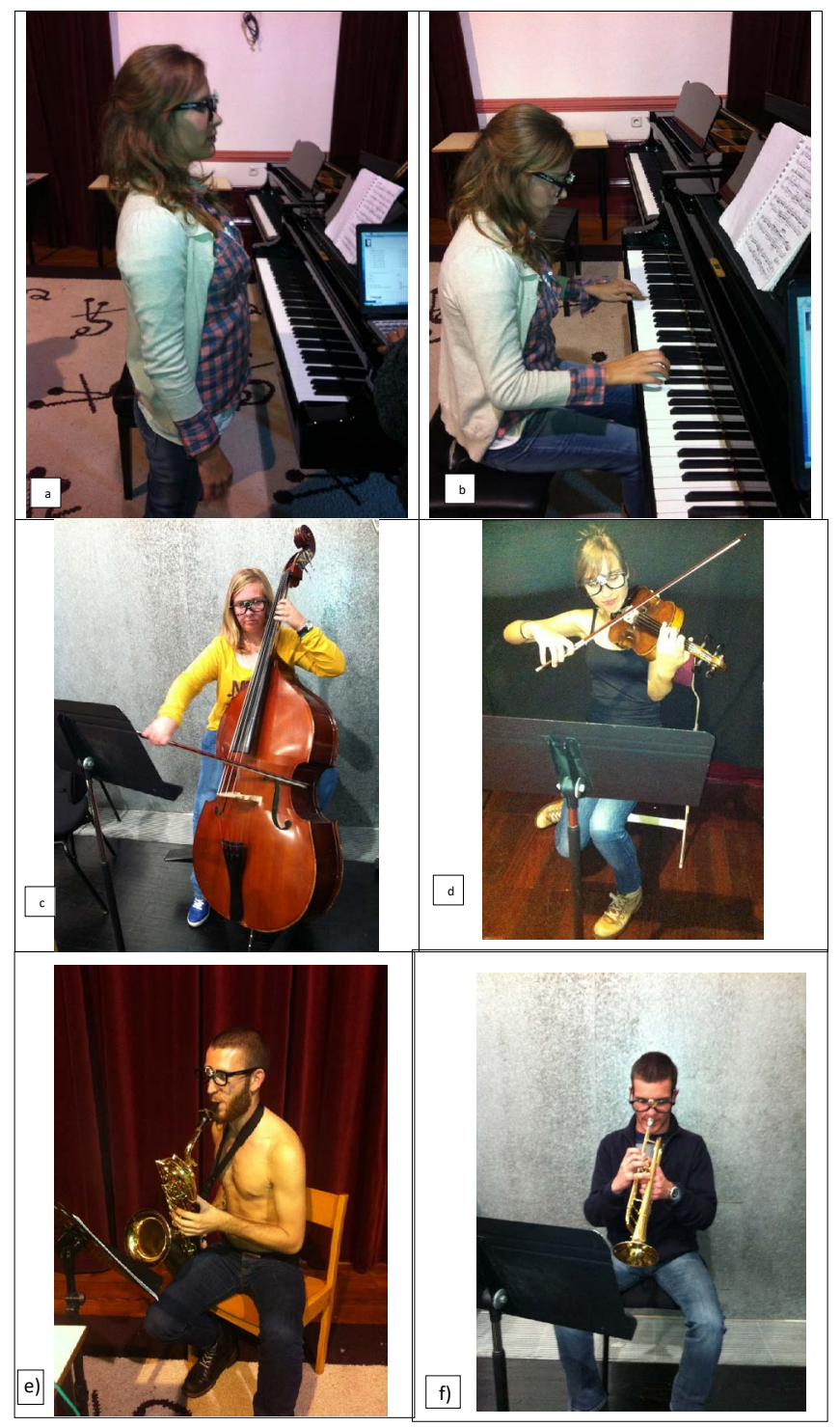

Figure 1. a) Pianist standing in a straight position and looking forward during the calibration of the accelerometer; Three different instrumentalists playing their instrument in a sited position while the accelerometer's signal is being read by the program ZSTAR Graphical User Interface ${ }^{\circledR}$, b) pianist, c) cello player , d) violinist, e) Saxophonist, and f) trumpet player

\section{Results}

Figures 2 and 3 represent the graphic obtained of a violinist and a saxophonist after processing the signal captured from the accelerometer with the program ZSTAR Graphical User Interface. All participants obtained a similar graphic which corresponds to the movement pattern while playing in a sited position. The red line corresponds to the inclination in an antero-posterior direction, thus a positive value is representative of an anterior flexion of the head and neck, and a negative value to a posterior extension of the head and neck. The blue line corresponds to the flexion in a lateral direction, thus a positive value corresponds to a flexion of the head to the right side and a negative value corresponds to a flexion of the head to the left side. When it was asked to the participants to be in a straight position and looking forward, the linear graph obtained was flat for both lines where the values were in the range of \pm 5 degrees. 


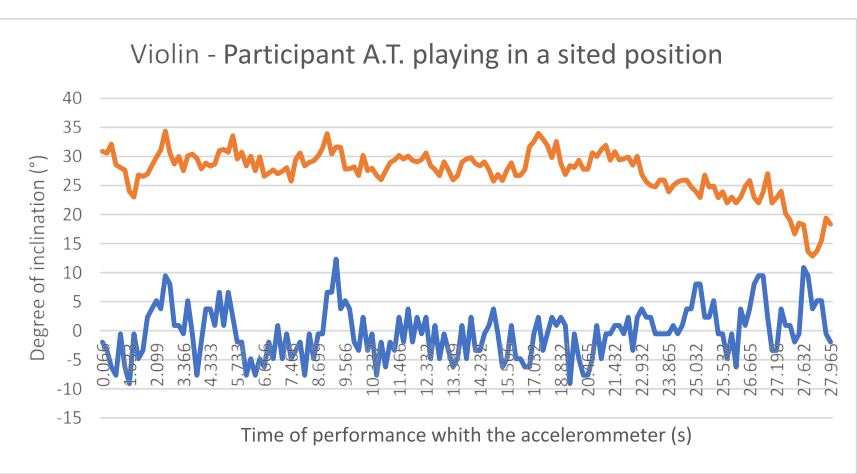

Figure 2. Represents the linear graphic obtained after processing the signal captured from the accelerometer with the program ZSTAR Graphical User Interface ${ }^{\circledR}$

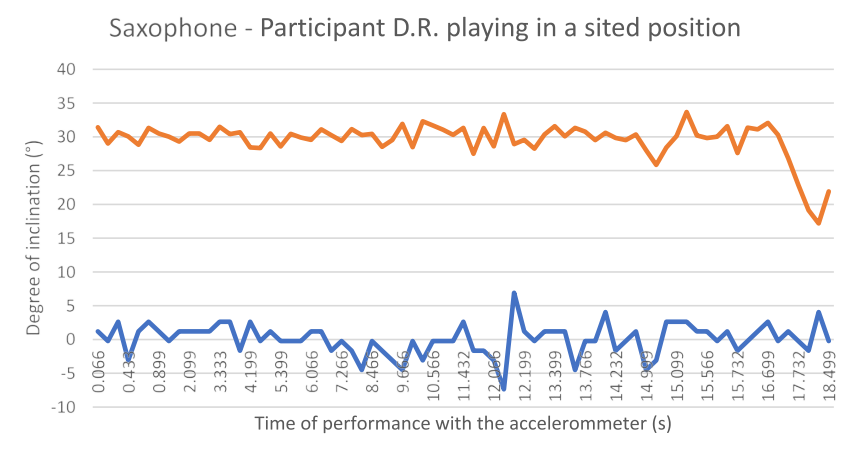

Figure 3. Represents the signal captured from the accelerometer with the program ZSTAR Graphical User Interface ${ }^{\circledR}$, saxophonist player

For all participants it was calculated the average value for the range of motion while in a straight position and when playing their instrument in a sited position. For example, A.T., when playing adopt a slight inclination of her head to the right side $\left(1.73^{\circ}\right)$ and with an anterior flexion of the head of $27.32^{\circ}$. Table 1 represents the average value for the participants of the study regarding the axis $\mathrm{X}$ (lateral inclination of the head, in a left-right direction) and Table 2 represents the average value for the participants regarding the axis Y (anterior-posterior inclination of the head and neck, in a forward-back direction). On both tables, the $\mathrm{X}$ refers to the absence of representative values regarding the acquisition data due to artefacts in the signal.

\section{Discussion}

The study have shown substantial differences regarding the range of motion of the head and neck in the axis Y between the group of wind instruments and string instruments. Within the wind instrumentalists group, the saxophonists showed to have more anterior position of the head when compared with the clarinettists. Out of 10 saxophonists, 9 showed to have an anterior flexion of the head around $25^{\circ}$ during their musical performance. On the other hand, in the group of clarinettists, from 5 participants, only 1 participant had a greater value than $25^{\circ}$ while the other participants had smaller values. For the lateral flexion of the head, the clarinettists showed a more stable position than the saxophonists, with less oscillation in a left-right direction. The different type of saxophone may be an important factor regarding the lateral inclination of the head, because when increasing the size of the saxophone the instrument will be at the right side of the body of the musician. Moreover, for a correct adaptation of the CCMC the mouthpiece that appears from the left side of the musician and therefore his/her head will present a lateral flexion to the left side. The single reed instrumentalists showed to have a static anterior position of the head and have a more dynamic variation in terms of the lateral inclination.

Because the double reed instrumentalists were only 5 , the findings are limited in number. For the double reed instrumentalists, 2 bassoon players showed a preference for the left side while playing their instrument, $-13^{\circ}$ and $-9^{\circ}$. Once, the bassoon is held diagonally in front of the musician and rest the curve of the right hand where the thumb joins the palm against the right groin. Also, both oboe players showed to prefer the left side, although with a smaller inclination, $-1^{\circ}$ and $-5^{\circ}$. Regarding to the anterior position of the head, the values were found to go from $25^{\circ}$ to $35^{\circ}$ for the oboes and from $22^{\circ}$ to $32^{\circ}$ for the bassoons.

In the brass instrumentalists, the greatest anterior flexion of the head was found for the trombone, which can be related to its musical gesture. The trombone player has his/her right hand on the brace moving forward and backward. For 3 trombone players, the anterior flexion of the head was found to be around $30^{\circ}$, for the 2 tuba players this value was $17^{\circ}$. The trumpetist also had an average value of $17^{\circ}$ anterior flexion of the head when playing. Regarding the axis X (left and right inclination) the values found were of little inclination, with the exception of a tuba player that had $-11^{\circ}$ and one french horn player with $7^{\circ}$. The position of a brass player, the size of the instrument and the position adopted when playing sited reflect on the axis $\mathrm{X}$ and $\mathrm{Y}$.

The transversal flute and the bisel flute were the wind instruments with the greatest range of motion when analysing the amplitude of the captured signal. As known, a musician will vary the body movement during its musical performance depending on the play, type of instrument and his/her personality. The four transversal flute musicians showed a tendency to flex laterally the head to their right side when playing. Furthermore, the only bisel flute showed to have a greater anterior flexion of the head when comparing with the transversal flute instrumentalists.

The violinists showed to have an anterior flexion of the head over than $25^{\circ}$ and all the 7 violinists showed to have a preference for a right lateral flexion of the head when playing, in a range of $2^{\circ}$ to $23^{\circ}$. Since, this string instrument require its stabilization with the menton and shoulder, and it is positioned on the left side of the musician, the head of the violinist will invariably incline to the opposite side. The same was found for the viola players, when all instrumentalists flexed to the right side with the exception of one. The viola is a string instrument similar to the violin, but bigger in size. Additionally, the viola players, although had also an anterior flexion of the head and neck going from $20^{\circ}$ to $37^{\circ}$, it was comparatively less than the violins. Once again, because of the volume of the instrument, the viola player could not flex anteriorly with the same facility as the violinist. The cello players showed to flex anteriorly greater than the violinists and viola players. The reason to this fact may be related to the musical gesture of the cello player that has to adopt to play its instrument. While the viola players and violinists had the strings and bow at the level of the shoulder, the cello player will have the instrument's strings and bow at the level of the abdomen.

Finally, the only pianist studied showed an anterior flexion of the head with values reaching $60^{\circ}$ and in average $38^{\circ}$. Regarding the lateral flexion of the head, there was a range of $20^{\circ}$ as the pianist moved the CCMC from the right to the left side during music performance.

All strings and wind instrumentalists play seated tilting more $20^{\circ}$ the head earlier than in an upright position and looking ahead.

Transverse flautists, violinists, violoncello instrumentalists play with their heads tilted to the right because of the musical gesture. 
Table 1. Represents the average value for the participants of the study regarding the axis $X$ (lateral flexion of the head, in a left-right direction)

\begin{tabular}{|c|c|c|c|c|c|c|}
\hline \multicolumn{7}{|l|}{ Axis X (Left-right direction) } \\
\hline Type of instrument & \multicolumn{2}{|c|}{ CELLO } & & & & \\
\hline Participants & R.F. & D.S. & & & & \\
\hline Straight position (looking forward) & -0.82 & -1.40 & & & & \\
\hline Playing in a sitted position & -1.29 & 5.26 & & & & \\
\hline Type of instrument & \multicolumn{6}{|c|}{ VIOLA } \\
\hline Participants & A.C. & E.R. & E.V. & H.L. & J.R. & M.J.A. \\
\hline Straight position (looking forward) & -0.66 & -0.42 & -0.75 & 0.58 & -2.04 & 2.33 \\
\hline Playing in a sitted position & 11.19 & 14.79 & 0.25 & 15.80 & -1.54 & 6.64 \\
\hline
\end{tabular}

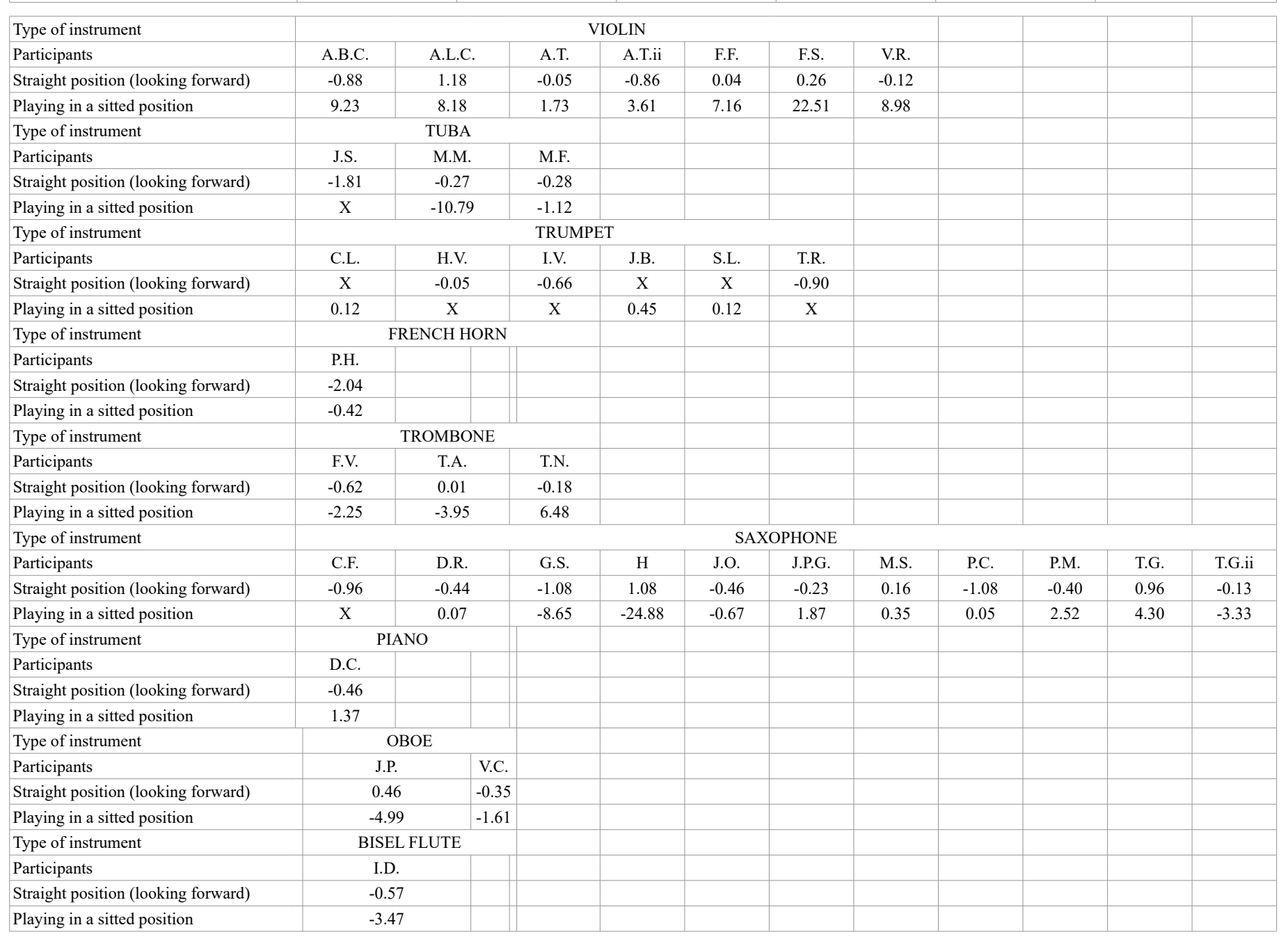

\begin{tabular}{|c|c|c|c|c|c|c|c|}
\hline Type of instrument & \multicolumn{4}{|c|}{ Transverse FLUTE } & & & \\
\hline Participants & F.S. & H. & M.J.B. & N.S. & & & \\
\hline Straight position (looking forward) & 1.15 & -0.26 & 0.73 & 0.34 & & & \\
\hline Playing in a sitted position & 20.88 & 14.36 & 20.85 & 13.82 & & & \\
\hline Type of instrument & \multicolumn{3}{|c|}{ BASSOON } & & & & \\
\hline Participants & A.M. & A.B. & P.R. & & & & \\
\hline Straight position (looking forward) & -1.13 & 0.26 & -1.08 & & & & \\
\hline Playing in a sitted position & -0.25 & -13.09 & -9.06 & & & & \\
\hline Type of instrument & \multicolumn{7}{|c|}{ CLARINET } \\
\hline Participants & C.F. & D.S. & F.R. & G.F. & J.P. & J.V. & L.M. \\
\hline Straight position (looking forward) & -0.05 & -2.22 & $\mathrm{X}$ & $\mathrm{X}$ & $\mathrm{X}$ & -0.53 & $\mathrm{X}$ \\
\hline Playing in a sitted position & -2.83 & $\mathrm{X}$ & 1.24 & 2.27 & -6.29 & $\mathrm{X}$ & -2.08 \\
\hline
\end{tabular}


Table 2. Represents the average value for the participants regarding the axis $Y$ (anterior-posterior inclination of the head and neck, in a forward-back direction)

\begin{tabular}{|c|c|c|c|c|c|c|c|c|c|c|c|}
\hline \multicolumn{12}{|l|}{ Axis Y (Forward-back direction) } \\
\hline Type of instrument & \multicolumn{2}{|c|}{ CELLO } & & & & & & & & & \\
\hline Participants & R.F. & D.S. & & & & & & & & & \\
\hline Straight position (looking forward) & 19.30 & 15.07 & & & & & & & & & \\
\hline Playing in a sitted position & 38.97 & 34.15 & & & & & & & & & \\
\hline Type of instrument & \multicolumn{6}{|c|}{ VIOLA } & & & & & \\
\hline Participants & A.C. & E.R. & E.V. & H.L. & J.R. & M.J.A. & & & & & \\
\hline Straight position (looking forward) & 3.39 & 15.17 & 12.95 & 17.34 & 9.30 & 6.25 & & & & & \\
\hline Playing in a sitted position & 20.38 & 35.48 & 32.75 & 37.57 & 29.38 & 27.80 & & & & & \\
\hline Type of instrument & \multicolumn{7}{|c|}{ VIOLIN } & & & & \\
\hline Participants & A.B.C. & A.L.C. & A.T. & A.T.ii & F.F. & F.S. & V.R. & & & & \\
\hline Straight position (looking forward) & 20.09 & 21.04 & 20.84 & 12.32 & 15.11 & 11.54 & 19.54 & & & & \\
\hline Playing in a sitted position & 40.41 & 36.16 & 27.32 & 26.99 & 35.48 & 26.81 & 37.32 & & & & \\
\hline Type of instrument & \multicolumn{3}{|l|}{ TUBA } & & & & & & & & \\
\hline Participants & J.S. & M.M. & M.F. & & & & & & & & \\
\hline Straight position (looking forward) & 10.79 & 11.31 & 10.80 & & & & & & & & \\
\hline Playing in a sitted position & $\mathrm{X}$ & 16.10 & 18.30 & & & & & & & & \\
\hline Type of instrument & \multicolumn{6}{|c|}{ TRUMPET } & & & & & \\
\hline Participants & C.L. & H.V. & I.V. & J.B. & S.L. & T.R. & & & & & \\
\hline Straight position (looking forward) & $\mathrm{X}$ & 19.03 & 15.48 & $\mathrm{X}$ & $\mathrm{X}$ & 16.72 & & & & & \\
\hline Playing in a sitted position & 12.76 & $\mathrm{X}$ & $\mathrm{X}$ & 25.24 & 23.96 & $\mathrm{X}$ & & & & & \\
\hline Type of instrument & \multicolumn{3}{|c|}{ FRENCH HORN } & & & & & & & & \\
\hline Participants & P.H. & & & & & & & & & & \\
\hline Straight position (looking forward) & 6.63 & & & & & & & & & & \\
\hline Playing in a sitted position & 16.81 & & & & & & & & & & \\
\hline Type of instrument & \multicolumn{3}{|c|}{ TROMBONE } & & & & & & & & \\
\hline Participants & F.V. & T.A. & T.N. & & & & & & & & \\
\hline Straight position (looking forward) & 16.85 & 12.39 & 9.44 & & & & & & & & \\
\hline Playing in a sitted position & 29.68 & 31.77 & 30.89 & & & & & & & & \\
\hline Type of instrument & \multicolumn{11}{|c|}{ SAXOPHONE } \\
\hline Participants & C.F. & D.R. & G.S. & $\mathrm{H}$ & J.O. & J.P.G. & M.S. & P.C. & P.M. & T.G. & T.G.ii \\
\hline Straight position (looking forward) & 14.04 & 15.66 & 13.37 & 19.09 & 20.80 & 10.52 & 14.36 & 15.13 & 15.90 & 24.78 & 11.77 \\
\hline Playing in a sitted position & $\mathrm{X}$ & 29.55 & 35.06 & 30.24 & 24.00 & 27.14 & 27.72 & 26.83 & 38.43 & 33.75 & 27.71 \\
\hline Type of instrument & \multicolumn{2}{|c|}{ PIANO } & & & & & & & & & \\
\hline Participants & D.C. & & & & & & & & & & \\
\hline Straight position (looking forward) & 2.06 & & & & & & & & & & \\
\hline Playing in a sitted position & 37.91 & & & & & & & & & & \\
\hline Type of instrument & \multicolumn{2}{|l|}{ OBOE } & & & & & & & & & \\
\hline Participants & J.P. & V.C. & & & & & & & & & \\
\hline Straight position (looking forward) & 15.80 & 20.71 & & & & & & & & & \\
\hline Playing in a sitted position & 24.70 & 34.98 & & & & & & & & & \\
\hline Type of instrument & \multicolumn{2}{|c|}{ BISEL FLUTE } & & & & & & & & & \\
\hline Participants & I.D. & & & & & & & & & & \\
\hline Straight position (looking forward) & 10.79 & & & & & & & & & & \\
\hline Playing in a sitted position & 33.45 & & & & & & & & & & \\
\hline Type of instrument & \multicolumn{4}{|c|}{ Transverse FLUTE } & & & & & & & \\
\hline Participants & F.S. & H. & M.J.B. & N.S. & & & & & & & \\
\hline Straight position (looking forward) & 15.81 & 8.17 & 11.97 & 7.96 & & & & & & & \\
\hline Playing in a sitted position & 27.49 & 21.43 & 24.65 & 15.74 & & & & & & & \\
\hline Type of instrument & \multicolumn{3}{|c|}{ BASSOON } & & & & & & & & \\
\hline Participants & A.M. & A.B. & P.R. & & & & & & & & \\
\hline Straight position (looking forward) & 20.18 & 8.22 & 26.07 & & & & & & & & \\
\hline Playing in a sitted position & 22.52 & 32.56 & 30.21 & & & & & & & & \\
\hline Type of instrument & \multicolumn{7}{|c|}{ CLARINET } & & & & \\
\hline Participants & C.F. & D.S. & F.R. & G.F. & J.P. & J.V. & L.M. & & & & \\
\hline Straight position (looking forward) & 11.24 & 12.26 & $\mathrm{X}$ & $\mathrm{X}$ & $\mathrm{X}$ & 15.83 & $\mathrm{X}$ & & & & \\
\hline Playing in a sitted position & 29.74 & $\mathrm{X}$ & 25.53 & 17.59 & 24.17 & $\mathrm{X}$ & 16.63 & & & & \\
\hline
\end{tabular}


Violinists and violetists must hold/stabilize the instrument with the chin and shoulder and the cellists support the instrument on its left shoulder. The transverse flautists turn their heads to the right side because the instrument comes from left to right.

The bassoon was the only instrument that seemed to have a tendency to slightly tilt the head to the left, as it is supported on the right hip and the mouthpiece comes out on the left side.

The musician depends of its CCMC. Therefore, the accelerometer allowed to determine with accuracy the biomechanics of the head and neck during the musical performance of wind and string instrumentalists.

According to previous data obtained by the accelerometer (joint motion arch angles and segments spatial displacement) associated with biomechanical and ergonomic factors presented during musical performance, it can be presumed that in case of technical postures with prolonged duration and/or intermittent/repetitive motion angles/ movements for several hours per day (training duration) [12], joint and muscular overload may occur, as well as other pathophysiological situations which predispose to the onset of over-use MSD [17]. These MSD include: joint and/or muscular pain [14,18], muscular retraction versus distension, postural disorders with inappropriate and intermittent non-physiological postures [19], compensatory muscular contractures in postural disorders and muscular imbalances, appearance of intramuscular tense bands and trigger points (active or latent in frequent activation) [20], joint wear, intervertebral discs, vertebral disorders, craniomandibular dysfunction [21], shoulder tendinopathies (directly or indirectly consecutive to technical gesture). So, lesions or disorders caused by overload and repetition microtraumas ultimately cause functional limitation, inability to perform the correct or more physiological technique and decrease in musical performance, which can be evaluated interdisciplinary with several diagnosis procedures and intervened by rehabilitation programs [22].

The authors would like to highlight that within the results of our study, the maintenance of these postures by the string and wind instrumentalists, with their repetitive movements and gesture technique can eventually in the future be associated with:

-the anterior cervical tilt posture greater than or equal to $20^{\circ}-25^{\circ}$ which favors among others, the cervical and mandibular spatial anterior displacement, often associated with internal rotation and bearing of the shoulders, cervical flexor muscles retraction and overload (with pain) of the cervical extensor muscles, tension myalgias, occipital tension headaches, myofascial pain with or without active trigger points.

-the rotation and lateral inclination to one side, associated to technical gesture repetition chronicity causes, among others, isometric muscle contractions, homolateral muscle shrinkage, compensatory contralateral muscular contraction (not only at the cervical but also dorsal and lumbar levels; and especially if associated with movements and compensatory paradoxes rotation-inclination postures of the trunk and sometimes of the pelvic girdle), joint overloads in the context of rotation-inclination and/or translation, heterogeneity in the type of muscular contraction in symmetrical planes, visual disorders with different visual accommodations, tension headaches. This body postures can influence and/or augment fatigue and musculoskeletal complaints in musicians (Badjou et al; 2011) as others disorders like energy expenditure dysfunction [24].

The accelerometer by giving quantitative data of the movement and postures adopted by the CCMC allows to associate these measurements with the clinical data (including physical examination and pain assessment). Thus, bringing, indirectly, somewhat explicitness to better comprehend the muscular groups that are involved and play an important role to the stabilization of the instrument, but also that participate in the musical technical gesture contributing for the understanding of the occurrence of musculoskeletal complaints among professional musicians [24].

This may have an important role in the "preventive" medicine (correcting or perfecting the technical gesture and preventing potential sequels) and in "therapeutic" medicine (assisting in the understanding of the pathophysiological and biomechanical mechanisms that cause injury, in the clinical-functional diagnosis, in functional limitation and disability and on the therapeutic measures to be taken).

This is the first of several evaluation studies, concerning technical gesture, segments spatial displacement, biomechanics, pain, musculoskeletal complaints and examination, types of muscular contraction, postural disorders and compensation strategies in peri and post-training musical performance, associating technologies (accelerometer), as a complementary assessment, with the subjective and physical examination of the musician.

\section{Study Limitations}

Firstly, although the study sample was composed by 57 participants, there was not a similar number of musicians for each type of instrument. Nevertheless, this sample is representative of most of the orchestra musicians apart from the harpist, which allows to obtain valid information regarding the postures adopted by the CCMC during musical performance.

\section{Conclusion}

The use of the accelerometer allowed to analyze the body movement (joint motion arch angles and segments spatial displacement) dynamically and statically.

The musician depends on its CCMC and segments spatial displacement. Therefore, the accelerometer allowed to determine with accuracy the biomechanics of the head and neck during the musical performance of wind and string instrumentalists

In general, all instrumentalists had more $20^{\circ}$ of anterior flexion of the head when playing in a sited position comparing to the straight position. Relatively to the lateral inclination of the head, the cello players had a preference for the right side, such as, the violin, the viola and the transversal flute players. The bassoon players show a tendency to have a left lateral flexion of the head when playing. For the rest of the instrumentalists the lateral flexion of the head was minimum when playing.

The accelerometer by giving quantitative data of the arch of movement and postures allows to associate these measurable data with the clinical data (including physical examination, joint-muscle evaluation and pain assessment) with implications in prevention and therapeutic strategies.

All the present results enrich performing arts medicine, knowing that the relationship between performing arts medicine and dentistry is yet little explored. Further studies shall have to be done.

\section{Acknowledgements}

The authors gratefully acknowledge the funding of projects with references NORTE-01-0145-FEDER-000022 and project LAETA UID/EMS/50022/2013. 


\section{References}

1. Chan C, Ackermann B (2014) Evidence-informed physical therapy management of performance-related musculoskeletal disorders in musicians. Front Psychol 5: 706. [Crossref]

2. Kok LM, Huisstede BM, Voorn VM, Schoones JW, Nelissen RG (2016) The occurrence of musculoskeletal complaints among professional musicians: a systematic review. Int Arch Occup Environ Health 89: 373-396. [Crossref]

3. Kok LM, Vlieland TP, Fiocco M, Nelissen RG (2013) A comparative study on the prevalence of musculoskeletal complaints among musicians and non-musicians. $B M C$ Musculoskelet Disord 14: 9. [Crossref]

4. Altenmüller E, Jabusch HC (2010) Focal dystonia in musicians: phenomenology, pathophysiology, triggering factors, and treatment. Med Probl Perform Art 25: 3-9. [Crossref]

5. Brandfonbrener AG (2003) Musculoskeletal problems of instrumental musicians. Hand Clin 19: 231-239. [Crossref]

6. Leaver R, Harris EC, Palmer KT (2011) Musculoskeletal pain in elite professional musicians from British symphony orchestras. Occup Med (Lond) 61: 549-555. [Crossref]

7. Chan C, Driscoll T, Ackermann BJ (2014) Effect of a musicians' exercise intervention on performance-related musculoskeletal disorders. Med Probl Perform Art 29: 181188. [Crossref]

8. McCrary JM, Halaki M, Ackermann BJ (2016) Effects of Physical Symptoms on Muscle Activity Levels in Skilled Violinists. Med Probl Perform Art 31: 125-131. [Crossref]

9. Silva AG, Lã FM, Afreixo V (2015) Pain prevalence in instrumental musicians: a systematic review. Med Probl Perform Art 30: 8-19. [Crossref]

10. Ramella M, Fronte F, Converti RM (2014) Postural disorders in conservatory students: the Diesis project. Med Probl Perform Art 29: 19-22. [Crossref]

11. Piątkowska K, Wnuk B, Blicharska I, Rychlik M, Durmała J (2016) Cervical Pain in Young Professional Musicians - Quality of Life. Ortop Traumatol Rehabil 18: 21-29. [Crossref]

12. Amiri M, Jull G, Bullock-Saxton J (2003) Measuring range of active cervical rotation in a position of full head flexion using the 3D Fastrak measurement system: an intratester reliability study. Man Ther 8: 176-179. [Crossref]
13. Takasaki H, Hall T, Oshiro S, Kaneko S, Ikemoto Y, et al. (2011) Normal kinematics of the upper cervical spine during the Flexion-Rotation Test - In vivo measurements using magnetic resonance imaging. Man Ther 16: 167-171. [Crossref]

14. Edmondston SJ, Henne SE, Loh W, Ostvold E (2005) Influence of cranio-cervical posture on three-dimensional motion of the cervical spine. Man Ther 10: 44-51. [Crossref]

15. Salvia P, Champagne O, Feipel V, Rooze M, de Beyl DZ (2006) Clinical and goniometric evaluation of patients with spasmodic torticollis. Clin Biomech (Bristol, Avon) 21: 323-329. [Crossref]

16. Minami I, Oogai K, Nemoto T, Nakamura T, Igarashi Y, et al. (2010) Measurement of jerk-cost using a triaxial piezoelectric accelerometer for the evaluation of jaw movement smoothness. J Oral Rehabil 37: 590-595. [Crossref]

17. Bird HA (2013) Overuse Syndrome in musicians. Clin Rheumatol 32: 475-479. [Crossref]

18. Steinmetz A, Scheffer I, Esmer E, Delank KS, Peroz I (2015) Frequency, severity, and predictors of playing-related musculoskeletal pain in professional orchestral musicians in Germany. Clin Rheumatol 34: 965-973. [Crossref]

19. Berque P, Gray H, McFadyen A (2016) Playing-Related Musculoskeletal Problems among Professional Orchestra Musicians in Scotland: A Prevalence Study Using a Validated Instrument, the Musculoskeletal Pain Intensity and Interference questionnaire for Musicians (MPIIQM). Med Probl Perform Art 31: 78-86. [Crossref]

20. Blanco-Piñero P, Diaz-Pereira MP, Martinez Vidal A (2018) Variation in posture quality across musical instruments and its impact during performances. Int J Occup Saf Ergon 24: 316-323. [Crossref]

21. Shah JP, Thaker N, Heimur J, Aredo JV, Sikdar S, et al. (2015) Myofascial Trigger Points Then and Now: A Historical and Scientific Perspective. $P M R$ 7: 746-761. [Crossref]

22. Steinmetz A, Zeh A, Delank KS, Peroz I (2014) Symptoms of craniomandibular dysfunction in professional orchestra musicians. Occup Med (Lond) 64: 17-22. [Crossref]

23. Ross M, Roy JS (2018) Effect of a rehabilitation program on performance-related musculoskeletal disorders in student and professional orchestral musicians: a randomized controlled trial. Clin Rehabil 32: 1656-1665. [Crossref]

24. Baadjou V, Van Eijsden-Bessling M, Samama-Polak A, Smeets R, Passos V, et al. (2011) Energy Expenditure in Brass and Woodwind Instrumentalists. Med Probl Perform Art 26: 218-223. [Crossref]

Copyright: (C2018 Clemente MP. This is an open-access article distributed under the terms of the Creative Commons Attribution License, which permits unrestricted use, distribution, and reproduction in any medium, provided the original author and source are credited. 